Revista Brasileira de Agricultura Irrigada v.10, no.6, p. 1086 - 1095, 2016

ISSN 1982-7679 (On-line)

Fortaleza, CE, INOVAGRI - http://www.inovagri.org.br

DOI: $10.7127 /$ rbai.v10n600539

Protocolo 539.16 - 29/11/2016 Aprovado em 23/12/2016

\title{
BIOMETRIA E ÓLEO ESSENCIAL DE ALECRIM PIMENTA CULTIVADO EM DIFERENTES ÉPOCAS E CONDIÇÕES DE LUMINOSIDADE
}

\author{
Maria da Saúde de Sousa Ribeiro ${ }^{1}$, Rafael Santiago da Costa $^{2}$, Aiala Vieira Amorim³ \\ Claudivan Feitosa de Lacerda ${ }^{4}$, Nildo da Silva Dias ${ }^{5}$
}

\begin{abstract}
RESUMO
O uso de medicamentos à base de espécies vegetais é uma prática que acompanha o ser humano desde os primórdios da civilização. Mudanças fisiológicas e anatômicas nos vegetais podem ocorrer em função de estresses, principalmente o luminoso. Neste contexto, objetivou-se com o presente trabalho, avaliar o crescimento e o rendimento de óleo essencial de alecrim pimenta (Lippia origanoides) nas condições edafoclimáticas do maciço de Baturité, Ceará. O delineamento utilizado foi inteiramente casualizado com parcelas subsubdivididas, sendo as parcelas definidas pelas duas estações: seca (agosto a novembro de 2013) e chuvosa (fevereiro a maio de 2014), as subparcelas formadas pelas condições de luminosidade: telado (casa de vegetação) e pleno sol e as subsubparcelas referentes às quatro épocas de avaliação ( $0,40,80$ e 120 dias após o transplantio), com cinco repetições. As variáveis avaliadas foram: área foliar, altura de planta, diâmetro do caule e a massa seca dos diferentes órgãos vegetais, bem como o rendimento do óleo essencial. Em relação aos resultados observou-se que a produção de biomassa seca de folhas não diferiu entre os dois ambientes após 120 dias cultivo. Os resultados mostraram também que houve alteração no padrão de crescimento do alecrim pimenta cultivado em ambiente telado, resultando em plantas mais altas, folhas maiores, maior área foliar, menor desenvolvimento do sistema radicular, e diminuição no rendimento do óleo essencial. A planta de alecrim pimenta é sensível a variação de temperatura, pois essa causa alterações em sua morfologia e fisiologia.
\end{abstract}

Palavras-chave: Lippia origanoides, Crescimento, Sazonalidade, Sombreamento.

\footnotetext{
${ }^{1}$ Doutoranda em Engenharia Agrícola, Universidade Federal do Ceará (UFC), Av. da Universidade, 2853 Benfica, CEP: 60020-180, Fortaleza - CE, Brasil, sauderibeiro@hotmail.com

${ }^{2}$ Graduando em Agronomia, Instituto de Desenvolvimento Rural, Universidade da Integração Internacional da Lusofonia Afro-Brasileira (UNILAB), Av. da Abolição, 3 - Centro, CEP: 62790-000, Redenção - CE, Brasil, rafaelsantiagodacosta@yahoo.com.br

${ }^{3}$ Professora Doutora, Instituto de Desenvolvimento Rural, UNILAB, Av. da Abolição, 3 - Centro, CEP: 62790000, Redenção - CE, Brasil, aialaamorim@unilab.edu.br

${ }^{4}$ Professor Doutor, UFC, Av. da Universidade, 2853 - Benfica, CEP: 60020-180, Fortaleza - CE, Brasil, claudivan_@hotmail.com

${ }^{5}$ Professor Doutor, Departamento de Solos, Universidade Federal Rural do Semi-Árido, Rua Francisco Mota, 572

- Alto de São Manoel, CEP: 59625-900, Mossoró - RN, nildo@ufersa.edu.br
} 


\title{
BIOMETRICS AND ESSENTIAL OIL OF PEPPER-ROSEMARY GROWN AT DIFFERENT TIMES AND LIGHT CONDITIONS
}

\begin{abstract}
The use in medicament of species plant is a practice that accompanies humans since the dawn of civilization. Physiological and anatomical changes of vegetables may occur in stress function, especially bright. In this context, aimed to of the present study was to evaluate the growth and the essential oil yield of pepper-rosemary (Lippia origanoides) at conditions of Maciço Baturité, Ceará state, Brazil. The design was completely randomized with split plots and, the plots defined by two seasons: dry (from August to November, 2013) and rainy (from February to May, 2014), the subplots formed by light conditions: shaded greenhouse) and unshaded (full sun evaluated at four times (0, 40, 80 and 120 days after transplanting), with five repetitions. The variables evaluated were: leaf area, height, stem thickness and dry mass of different plant organs, and the yield of essential oil. Regarding the results it revealed that the dry biomass of leaves did not differ between the two environments 120 days cultivation. The results also showed a significant change in rosemary pepper grown in a greenhouse environment, resulting in higher plants, larger leaves, larger leaf area, less development of the root system which indicates that the plant is light sensitive and decrease essential oil yield. The plant of pepper rosemary is sensitive to temperature variation because this causes changes in its morphology and physiology.
\end{abstract}

Keywords: Lippia origanoides, Growth, Shading, Seasonality.

\section{INTRODUCÃO}

O uso de medicamentos à base de espécies vegetais é uma prática que acompanha o ser humano desde os primórdios da civilização, sendo fundamentada no acúmulo de informações repassadas através de sucessivas gerações. No Brasil, o uso das plantas medicinais foi disseminado pela cultura indígena associada às tradições dos colonizadores europeus e, mais tarde, pelo ingresso dos africanos (FREIRE, 2004). Tal prática tem evoluído ao longo dos tempos, assumindo importante papel no tratamento de diversas doenças, de forma que, nas últimas décadas, o potencial medicinal de espécies vegetais vem sendo investigado no meio científico, buscando fundamentos para explicar as crenças populares de cura baseada em produtos vegetais (FREIRE, 2004).

Lippia origanoides Kunth, popularmente conhecida como alecrim-pimenta, é uma espécie de planta medicinal pertencente à família Verbenaceae, de porte ereto, com comprimento de até três metros de altura, apresenta folhas aromáticas e picantes, e além de ser considerada uma das sete espécies prioritárias da caatinga para conservação e manejo, essa planta medicinal possui grande potencial de uso pela indústria farmacêutica, por apresentar atividade antibacteriana e antifúngica devido à presença de óleo essencial rico em timol e carvacrol (LORENZI; MATOS, 2008).

Estudos com espécies medicinais têm evidenciado mudanças fisiológicas e anatômicas em função de estresses, principalmente o luminoso. Segundo Morais (2009), a radiação luminosa é essencial para o crescimento e desenvolvimento das plantas, que está diretamente ligada à fotossíntese e outros processos fisiológicos, bioquímicos e morfológicos. Plantas cultivadas em ambientes com pouca luz apresentam uma redução significativa em biomassa, com alterações na alocação para diferentes órgãos (SILVA et al., 2006) além de reduções no teor de óleo essencial e alterações na composição química (CHANG et al., 2008).

Além da radiação luminosa, as diferentes estações do ano, verão e inverno (condição seca e chuvosa), também podem acarretar 
diversas modificações no ambiente das plantas, influenciando no manejo e na produtividade final. Comparando-se as condições seca e chuvosa, no Estado do Ceará, verifica-se grande variabilidade temporal, com mudanças significativas nas variáveis meteorológicas, principalmente na insolação, umidade do ar e precipitação. Essas alterações nos elementos meteorológicos podem contribuir para modificar o padrão de desenvolvimento vegetativo, fisiológico e reprodutivo das plantas (LACERDA et al., 2010). Um exemplo disso, foi observado por Almeida et al. (2012), que verificaram um maior rendimento de teor de óleo essencial de 42 clones-elite de L. alba em plantas colhidas no período seco, e maior teor de linalol obtido de plantas colhidas no período chuvoso.

Nas condições climáticas brasileiras, consideradas tropicais e subtropicais, o aquecimento natural e demasiado pode causar problemas no cultivo das plantas em pleno sol. Para sanar estes problemas, em algumas regiões do Brasil, tem-se utilizado malhas de sombreamento para atenuar a densidade de fluxo de radiação solar, possibilitando o cultivo em épocas com alta disponibilidade energética (CALVETE et al., 2008). Diante do exposto, o objetivo do presente estudo foi avaliar o crescimento e o rendimento de óleo essencial de alecrim pimenta (Lippia origanoides) nos períodos seco e chuvoso, nas condições climáticas do maciço de Baturité, Ceará.

\section{MATERIAL E MÉTODOS}

O experimento foi conduzido durante a condição seca (agosto a novembro de 2013) e a condição chuvosa (fevereiro a maio de 2014), em uma área da fazenda experimental da Universidade Internacional da Lusofonia AfroBrasileira (UNILAB), localizada no Sítio Piroás, município de Redenção, no Maciço de

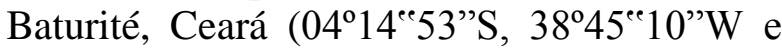
altitude média variando de 240 a $340 \mathrm{~m}$ ). O clima do local é classificado como Aw', ou seja, tropical chuvoso, muito quente, com predomínio de chuvas nas estações do verão e outono.

Dados de temperatura, umidade e luminosidade nas duas condições foram determinados com o auxílio de dois Data loggers (HOBO U12 Temperature/Relative Humidity/Light/External, Modelo: U12-012), sendo um destes dispostos dentro da casa telada enquanto o outro foi alocado no ambiente a pleno sol. Os dados eram coletados com uma frequência de 6 horas. Ao fim de cada avaliação, esses dados foram descarregados para que se calculassem os valores máximos, mínimos e médios das variáveis citadas acima, os quais podem ser observados na Tabela 1 .

Tabela 1. Valores médios de temperatura máxima (T. Máx.), mínima (T. Mín.) e média (T. Méd.), umidade relativa do ar máxima (UR. Máx.), mínima (UR. Mín.) e média (UR. Méd.) e luminosidade máxima (Lum. Máx.), mínima (Lum. Mín.) e média (Lum. Méd.), durante o período experimental no Maciço de Baturité, CE. 2014.

\begin{tabular}{lcccc}
\hline & \multicolumn{2}{c}{ Período Seco } & \multicolumn{2}{c}{ Período Chuvoso } \\
\hline & Telado & Pleno Sol & Telado & Pleno sol \\
\hline T. Máx. $\left({ }^{\circ} \mathrm{C}\right)$ & 36,56 & 39,54 & 34,00 & 37,80 \\
T. Mín. $\left({ }^{\circ} \mathrm{C}\right)$ & 23,67 & 23,71 & 21,10 & 20,70 \\
T. Méd. $\left({ }^{\circ} \mathrm{C}\right)$ & 30,11 & 31,62 & 27,55 & 29,20 \\
UR. Máx. (\%) & 94,50 & 91,46 & 98,44 & 99,04 \\
UR. Mín. (\%) & 25,55 & 20,04 & 40,45 & 49,49 \\
UR. Méd. (\%) & 60,02 & 55,75 & 69,44 & 74,26 \\
Lum. Max. (Lux) & $11.372,30$ & $32.201,20$ & $5.364,90$ & $24.427,80$ \\
Lum. Mín. (Lux) & 11,80 & 11,80 & 11,80 & 11.80 \\
Lum. Méd. (Lux) & $5.692,00$ & $16.106,50$ & $2.688,30$ & $12.219,80$ \\
\hline
\end{tabular}


Utilizou-se um delineamento inteiramente casualizado com parcelas subsubdivididas, sendo as parcelas definidas pelas duas estações (seca e chuvosa), as subparcelas formadas pelas condições de luminosidade (telado $50 \%$ e pleno sol), e as subsubparcelas pelas quatro épocas de avaliação (0, 40, 80 e 120 DAT). Foram utilizadas cinco repetições, sendo cada repetição representada por um vaso de 20 litros contendo uma planta.

Foram produzidas cerca de 120 mudas, de $L$. origanoides, por estaquia no Horto de plantas medicinais Professor Francisco José de Abreu Matos da Universidade Federal do Ceará (UFC), e para isso utilizou-se ramos herbáceos com aproximadamente $15 \mathrm{~cm}$ de comprimento, onde o substrato utilizado para o enraizamento era uma mistura de areia e esterco bovino (2:1). As estacas foram dispostas em copos plásticos descartáveis e armazenadas em uma estufa improvisada, feita de uma armação de ferro e coberta com plástico a fim de criar um microclima que propiciasse um melhor enraizamento. Após vinte dias, as mudas foram transplantadas para sacos plásticos pretos de polietileno contendo substrato composto de esterco e areia em uma proporção de (3:1). Posteriormente, as mudas foram transferidas para vasos plásticos pretos com capacidade para $20 \mathrm{~L}$, contendo solo predominante da região (dizer a classificação) o qual foi coletado para a análise dos macro e micronutrientes presentes no mesmo (Tabela 2).

Tabela 2. Atributos químicos do solo utilizado, coletado na camada de 0 a 0,20 m de profundidade.

\begin{tabular}{|c|c|c|c|c|c|c|c|c|c|c|c|}
\hline & $\begin{array}{c}\mathrm{N} \\
\left(\mathrm{g} \mathrm{Kg}^{-1}\right)\end{array}$ & $\mathrm{Ca}$ & $\mathrm{Mg}$ & $\begin{array}{l}\mathrm{Na} \\
(\mathrm{C}\end{array}$ & $\begin{array}{c}\mathrm{K} \\
\text { nolc K }\end{array}$ & $\begin{array}{l}\mathrm{H}+\mathrm{Al} \\
-1)\end{array}$ & $\mathrm{Al}$ & S & $\mathrm{Fe}$ & $\begin{array}{c}\mathrm{Cu} \quad \mathrm{Zn} \\
\left.(\mathrm{mg} \mathrm{Kg})^{-1}\right)\end{array}$ & $\mathrm{Mn}$ \\
\hline $\begin{array}{c}\text { Época Seca } \\
\text { Época }\end{array}$ & 0,90 & 3,40 & 1,40 & 0,10 & 0,32 & 1,98 & 0,10 & 5,2 & 6,7 & $\begin{array}{ll}0,6 & 2,1\end{array}$ & 9,7 \\
\hline Chuvosa & 0,71 & 4,50 & 1,70 & 1,60 & 0,21 & 0,17 & 0,00 & 8,0 & 11,2 & 0,6 & 20,4 \\
\hline
\end{tabular}

Após 0 transplantio as mudas permaneceram durante 10 dias em telado com $50 \%$ de luminosidade, a fim de se restabelecerem do estresse sofrido no transplantio e passassem a emitir novas raízes e folhas. Logo após esse período metade das mudas (60) foram levadas para fora da casa telada, submetidas a pleno sol, enquanto que as demais, protegidas na casa de vegetação.

A irrigação foi realizada com o uso do sistema de irrigação "Bubbler", o qual é recomendado para a agricultura familiar. No período seco a irrigação foi realizada a cada dois dias, mantendo-se o solo na capacidade de campo, já no período chuvoso a irrigação foi realizada apenas de forma suplementar, quando não se observou precipitações no local.

Aos 0, 40, 80 e 120 dias após o transplante (DAT) foram realizadas medições de altura e diâmetro do caule, utilizando-se uma régua graduada e um paquímetro digital, respectivamente. Após as medições de altura e diâmetro do caule, as plantas foram coletadas e a parte aérea fracionada em folhas e hastes. Em seguida, determinou-se a área foliar (AF), por meio de um medidor de superfície (LI 3100, Area Meter, Li-Cor., Inc., Lincoln, 87 Nebraska, USA).

Para determinação da massa do caule seco (MSC) e das folhas (MSF), os órgãos vegetais separados, foram colocados em estufa com circulação forçada de ar, a $65^{\circ} \mathrm{C}$ até atingir massa constante, sendo expressos em gramas. Após a coleta da parte aérea das plantas, o substrato de cultivo dos vasos foi coletado, sendo o seu conteúdo (solo + raízes) peneirado a fim de se separar as raízes do solo. Para a determinação da massa seca (MSR), as raízes foram lavadas, identificadas, e colocadas para secar em estufa, com circulação forçada de ar a $65^{\circ} \mathrm{C}$ até massa constante.

Já o óleo essencial foi obtido por hidrodestilação da borra do café à temperatura ambiente e ao abrigo da luz, em aparelho tipo Clevenger modificado. Para tanto, foram utilizados $130 \mathrm{~g}$ do material, acondicionados 


\section{CONDIÇÕES DE LUMINOSIDADE}

em balões de vidro de $2000 \mathrm{~mL}$, juntamente com $1500 \mathrm{~mL}$ de água destilada, sobre manta aquecedora e acoplada a aparelho do tipo Clevenger para a hidrodestilação do óleo. Após um período ininterrupto de 2 horas de destilação, foi anotado o volume de óleo essencial obtido em cada parcela.

A análise estatística dos dados foi realizada utilizando-se o programa “ASSISTAT 7.5 BETA”. A partir dos dados, realizou-se uma análise de regressão para os fatores quantitativos e em seguida foi feita uma análise comparativa das respostas das plantas nos períodos seco e chuvoso.

\section{RESULTADOS E DISCUSSÃO}

A.

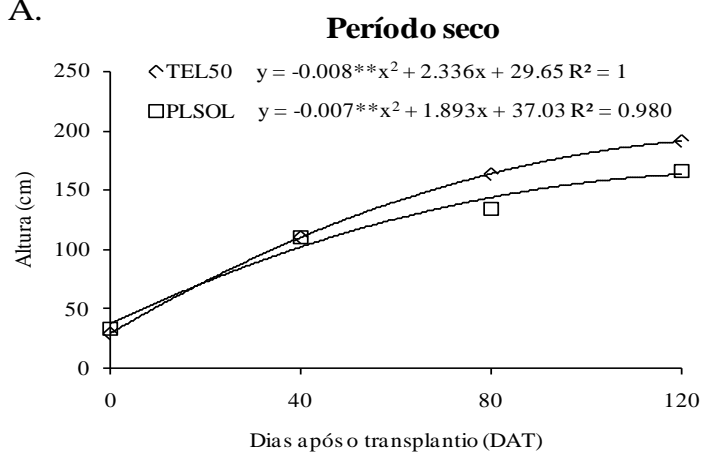

C.

Período seco

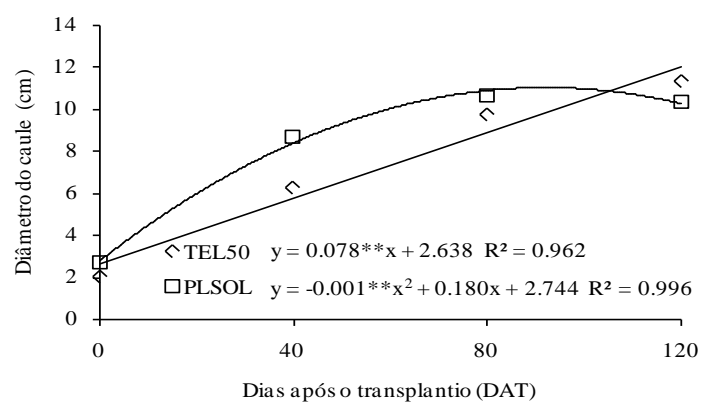

E.

Período seco

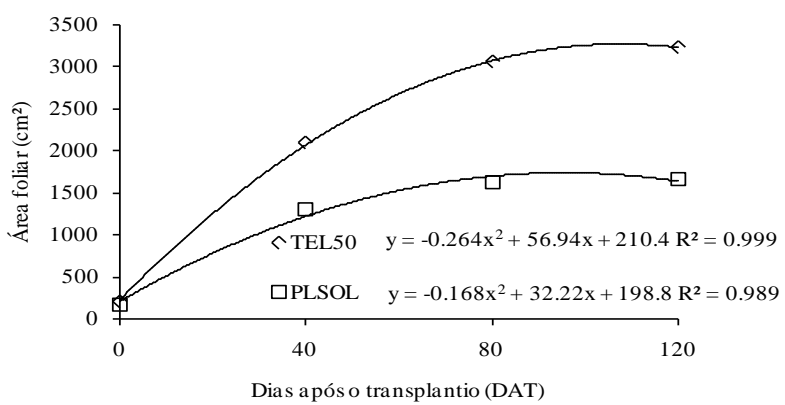

De forma geral, as plantas cultivadas no período seco e, também, aquelas cultivadas no período chuvoso, tiveram aumento na altura, diâmetro do caule e área foliar, ao longo do tempo nos dois ambientes de cultivo (telado e pleno sol). Os maiores valores de altura foram observados aos 120 DAT nas plantas cultivadas em telado, durante o período seco, sendo os valores médios obtidos iguais a 190,8 cm. Durante a condição seca as plantas de $L$. origanoides apresentaram respostas quadráticas com incremento de 2,33 e 1,89 cm dia $^{-1}$ nos ambientes telado e céu aberto, respectivamente (Figura 1A). Por outro lado, no período chuvoso a resposta foi linear, com um aumento unitário de 1,58 e $1,64 \mathrm{~cm} \mathrm{dia}^{-1}$ para o ambiente telado e pleno sol, respectivamente (Figura 1B).

B.

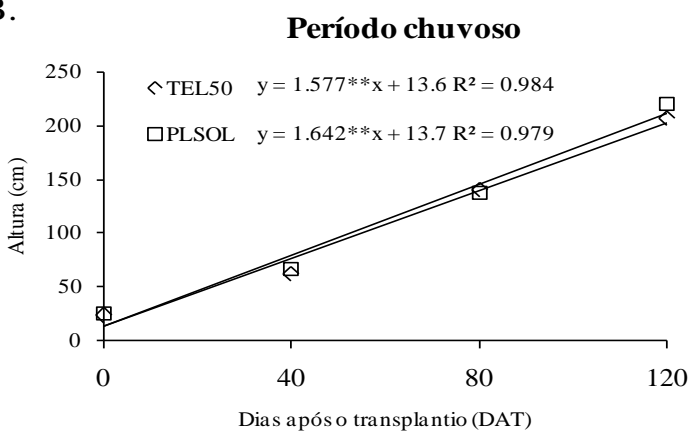

D.

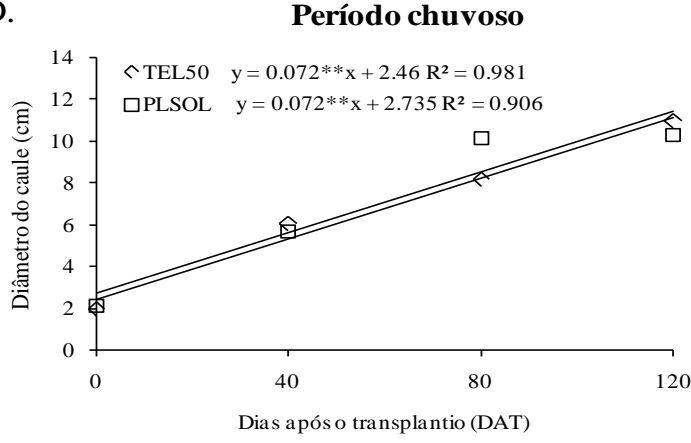

F.

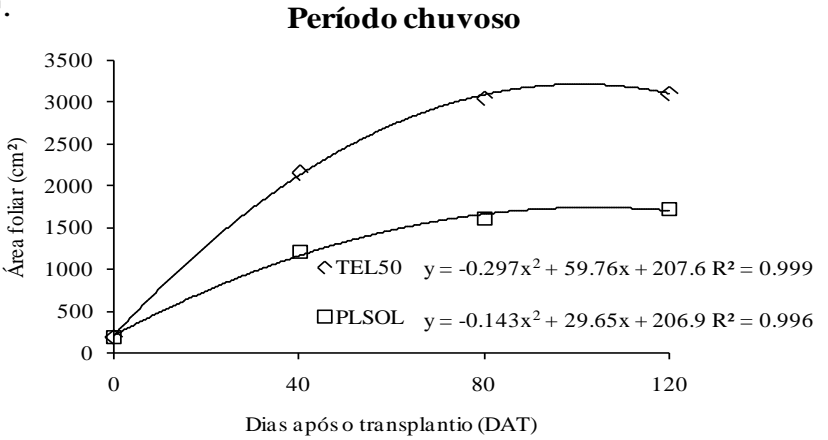


Figura 1. Altura (A) e (B), diâmetro do caule (C) e (D) e área foliar (E) e (F) em plantas de alecrim pimenta (Lippia origanoides) submetidas a dois períodos (seco e chuvoso), duas condições de luminosidades (telado $50 \%$ e pleno sol) e em épocas diferentes de avaliação (0, 40, 80 e 120 DAT), cultivadas no Maciço de Baturité, CE, 2014.

Para o diâmetro do caule, os valores encontrados foram maiores nas plantas cultivadas a céu aberto, exceto na última avaliação realizada aos 120 DAT no período seco (Figura 1C). Além disso, verifica-se que as diferenças entre telado e pleno sol foram menores nas plantas cultivadas no período chuvoso (Figura 1D). Observou-se um ajuste linear crescente para as plantas submetidas a telado no período seco, com ganho unitário de $0,078 \mathrm{~cm} \mathrm{dia}^{-1}$. Já para as plantas cultivadas sob pleno sol, ajustou-se uma equação quadrática, com um máximo valor de $8,1 \mathrm{~cm}$ para esta variável aos 42 DAT. Para o período chuvoso, independente do ambiente de cultivo (telado e pleno sol) foram observadas equações lineares com ganhos unitários de $0,072 \mathrm{~cm} \mathrm{dia}^{-}$ 1 .

Os maiores valores de área foliar foram de $3236,4 \mathrm{~cm}^{2}$ obtidos nas plantas cultivadas sob telado, independente do período de cultivo (seco e chuvoso). Essa resposta pode ser explicada pelo fato de anatomia foliar poder ser grandemente influenciada pela radiação solar recebida durante o crescimento, uma vez que a folha é um órgão plástico e sua estrutura interna adapta-se às condições externas do ambiente (SCHLUTER et al., 2003).

Os resultados de crescimento estão de acordo com os encontrados por Mattana et al. (2006), que constataram que plantas de Pothomorphe umbellata apresentaram diferenças significativas superiores na altura entre as plantas dos ambientes sombreados em comparação aos do pleno sol. Da mesma forma, Souza et al. (2007), trabalhando com alecrim pimenta em sombreamento, observaram que as plantas submetidas a ambiente sombreado apresentaram maiores alturas em relação as submetidas a luminosidade direta. Isso possivelmente ocorreu pelo fato das plantas que foram cultivadas sob telado estarem em um ambiente ameno e consequentemente mais propício ao crescimento da espécie.

Segundo Souza et al. (2012), as plantas de Melissa officinalis crescidas a pleno sol apresentaram maior diâmetro do colo que as plantas crescidas sob telado de $50 \%$ de luminosidade. Por outro lado, trabalhando com efeito de diferentes níveis de sombreamento no crescimento inicial de Unha de gato (Uncaria tomentosa), Lunz et al. (2014), observaram um acréscimo de diâmetro do caule a medida que se aumentou o sombreamento verificando-se o nível ótimo na condição de aproximadamente $60 \%$ de sombra. Esses resultados distintos, demonstram a especificidade de cada espécie, no caso de plantas $L$. origanoides, as respostas indicam que o tamanho do diâmetro do coleto foi influenciado significativamente pela condição luminosa e isso influenciou diretamente o peso da massa do caule seco.

De forma geral, observou-se que as massas das raízes secas (MSR), do caule (MSC) e das folhas, obtiveram aumento ao longo da época de avaliação, independente da condição de cultivo (Figura 2). O maior valor encontrado para MSR foi de 65,21 g obtido aos 120 DAT nas plantas que estavam em pleno sol, no período seco. Para os dois ambientes de cultivo (telado e pleno sol), nos dois períodos de avaliação (seco e chuvoso), foram encontradas respostas lineares crescentes. Os ganhos unitários das plantas, independente do período seco ou chuvoso, foram de 0,3 e $0,5 \mathrm{~g}$ dia $^{-1}$ para o ambiente telado e a pleno sol, respectivamente. 
A.

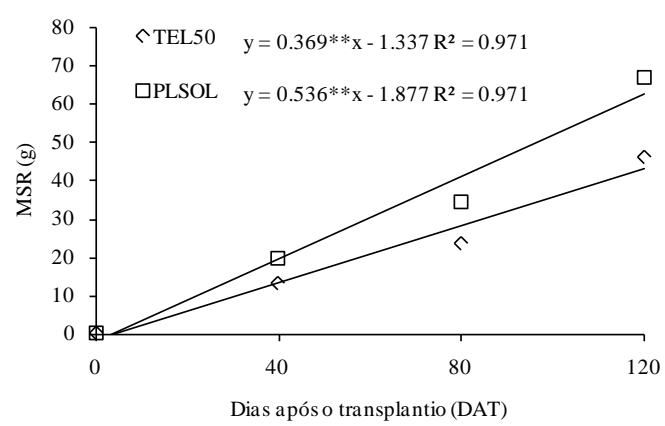

C.

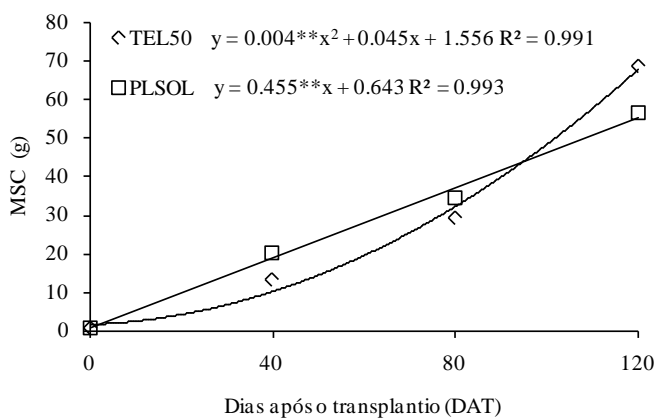

E.

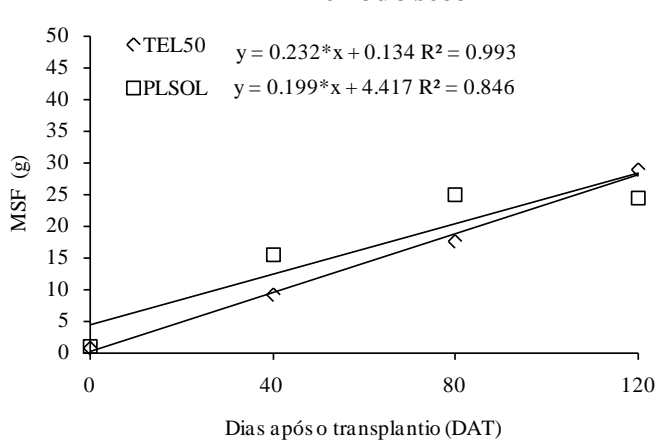

B.

Período chuvoso

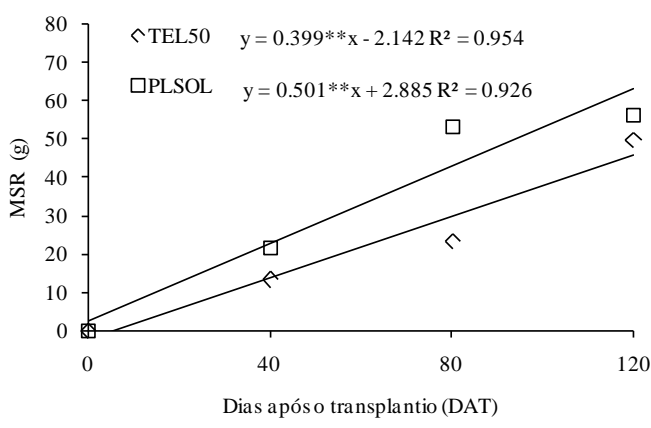

D.

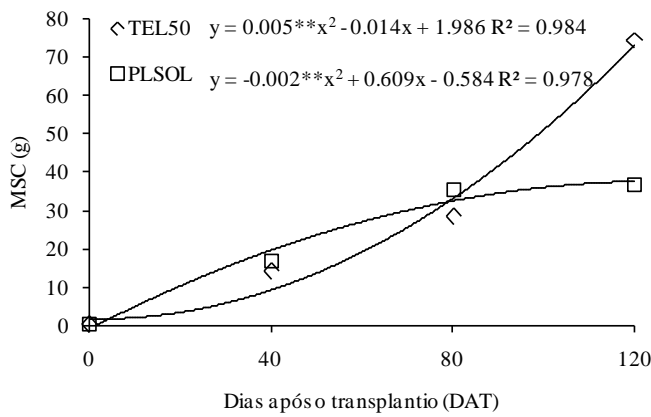

F.

Período chuvoso

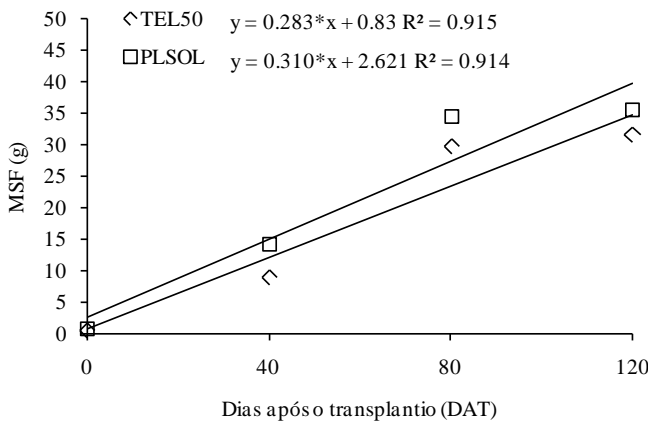

Figura 2. Massa seca da raiz (A) e (B), massa seca do caule (C) e (D) e massa seca das folhas (E) e (F) em plantas de alecrim pimenta (Lippia origanoides) submetidas a dois períodos (seco e chuvoso), duas condições de luminosidades (telado 50\% e pleno sol) e em épocas diferentes de avaliação (0, 40, 80 e 120 DAT), cultivadas no Maciço de Baturité, CE, 2014.

Para a massa do caule seco (MSC), verificou-se que o maior valor para essa variável foi de $72,31 \mathrm{~g}$ aos 120 DAT nas plantas cultivadas sob telado no período chuvoso. Comparando a primeira com a última coleta das plantas (0-120 DAT) no período seco, observou-se um aumento de 99,26\% e de 98,94\% na MSC das plantas cultivadas em telado e em pleno sol, respectivamente. Utilizando-se a mesma comparação no período chuvoso, verificouse um aumento de $98,89 \%$ da na MSC, para as plantas cultivadas em pleno sol e de 99,44\% para as plantas sob telado.

A massa das folhas secas (MSF) das plantas cultivadas no período seco ajustou-se a equações lineares crescentes com ganhos unitários de 0,23 e 0,19 g a cada dia para as condições telado e a pleno sol, respectivamente (Figura 2E). Resposta similar foi encontrada no período chuvoso com ganhos unitários de 0,28 e 0,31 g por dia para telado e pleno sol, respectivamente (Figura 2F). 
Resultados semelhantes aos observados neste trabalho foram detectados por outros autores. Oliveira et al. (2009), trabalhando com Artemisia vulgaris em diferentes tipos de ambientes, obtiveram maiores massas em diferentes órgãos vegetais quando as plantas foram cultivadas em pleno sol. Por outro lado, Batista et al. (2012), ao estudarem a planta Piper callosum verificaram que as melhores respostas para a massa seca das folhas ocorreram quando as plantas foram cultivadas em condições de menor nível de luminosidade.

As alterações ocorridas nos padrões de crescimento das plantas do L . origanoides com o uso de sombreamento constatam que a cultura é bastante influenciada pelas condições ambientais, ou seja, a atenuação da radiação solar com malha negra $50 \%$ torna as folhas da cultura progressivamente largas, com maior altura de planta, maior área foliar e menos crescimento radicular.

É importante ressaltar que, planta sombreada, restrita a radiação direta, tornamse mais eficiente na realização da fotossíntese, iniciando o processo em menor quantidade de radiação, se comparada à planta iluminada, pois respiram com menor intensidade e dessa forma compensam consideravelmente a redução do ganho de carbono nas condições de fraca iluminação (SCHAFER, 2009).

As diferenças nas variáveis de crescimento da $L$. origanoides obtidas em cultivos sombreado e a pleno sol reforça o fato de que a radiação solar interceptada e absorvida pelos vegetais é a fonte exclusiva de energia para os processos físicos, fisiológicos e bioquímicos, sendo de grande importância para determinação do acúmulo de massa seca e perda de água (MELO-ABREU et al., 2002).

Para o rendimento do óleo essencial observou-se que o ambiente de cultivo influenciou na quantificação do mesmo, de modo que as plantas submetidas a maiores luminosidades (pleno sol), durante o período seco, apresentaram um rendimento maior de óleo que as que estavam em ambiente telado. É importante ressaltar que a produção de folhas foi ligeiramente superior nas plantas sob telado aos 120 DAT, o que pode compensar parcialmente essa diferença. Os resultados observados no período chuvoso mostram similaridade entre os ambientes de cultivo quanto em termos de rendimento de óleo essencial (Tabela 3).

Tabela 3. Rendimento do óleo essencial de plantas de alecrim pimenta (Lippia origanoides) submetidas a dois períodos (seco e chuvoso) e duas condições de luminosidades (telado 50\% e pleno sol), cultivadas no Maciço de Baturité, CE.

\begin{tabular}{|c|c|c|c|}
\hline \multicolumn{2}{|c|}{ Período Seco (2013) } & \multicolumn{2}{|c|}{ Período Chuvoso (2014) } \\
\hline Telado & Pleno Sol & Telado & Pleno Sol \\
\hline \multicolumn{2}{|c|}{$\left(\mathrm{mL} \mathrm{g} \mathrm{g}^{-1}\right)$} & \multicolumn{2}{|c|}{$\left(\mathrm{mL} \mathrm{g} \mathrm{g}^{-1}\right)$} \\
\hline 1,51 & 2,02 & 1,46 & 1,52 \\
\hline
\end{tabular}

Estes resultados estão de acordo com os encontrados por Souza et al., (2007) que trabalhando com a influência do sombreamento na produção de fitomassa e óleo essencial em alecrim-pimenta verificaram que as plantas submetidas a luz plena apresentaram maiores rendimentos que as que estavam submetidas ao sombreamento progressivo com tela tipo sombrite (75\%, 50\% e $25 \%$ ), foram obtidos $0,48 \mathrm{~mL} \mathrm{~g}^{-1}$ para as plantas a sol pleno e $0,27 \mathrm{~mL} \mathrm{~g}^{-1}, 0,21 \mathrm{~mL} \mathrm{~g}^{-1}$ e $0,03 \mathrm{~mL} \mathrm{~g}^{-1}$ para as luminosidades 25,50 e $75 \%$ respectivamente. Então, o incremento do rendimento do óleo essencial está associado diretamente com a disponibilidade da luz, no caso do alecrim-pimenta os maiores valores foram encontrados quando as plantas foram cultivadas em pleno sol.

\section{CONCLUSÕES}

O cultivo em casa telada alterou o padrão de crescimento da $L$. origanoides, resultando em plantas mais altas, com folhas maiores, maior área foliar, menor desenvolvimento do 
sistema radicular, bem como diminuição no rendimento do óleo essencial, indicando assim à sensibilidade dessa espécie a iluminação plena.

\section{REFERÊNCIAS BIBLIOGRÁFICAS}

ALMEIDA, F. M.; COLOMBO, C. A.; SIQUEIRA, W. J. Produção e rendimento de óleo essencial de Lippia alba químiotipo linalol em função de duas épocas de colheita. In: $\quad 6^{\circ} \quad$ CONGRESSO INTERINSTITUCIONAL DE INICIAÇÃO CIENTÍFICA, Jaguariúna.

Resumos...Jaguariúna, SP, 2012. p.1-8.

BATISTA, A. C.; CHAVES, F. C. M.; MORAIS, R. R.; BRITO, A. U.; BIZZO, H. R. Produção de biomassa e teor de óleo essencial de plantas de óleo elétrico (Piper callosum Ruiz \& Pav.) em diferentes níveis de luminosidade nas condições de Manaus-AM. Horticultura brasileira, v.30, n.2, p.57975805, 2012.

CALVETE, E. O.; MARIANI, F.; WESP, C. D. L.; NIENOW, A. A.; CASTILHOS, T.; CECCHETTI, D. Fenologia, produção e teor de antocianinas de cultivares de morangueiro em ambiente protegido. Revista Brasileira de Fruticultura, v.30, n.2, p.396-401, 2008.

CHANG, X.; ALDERSON, P. G.; WRIGHT, C. J. Solar irradiance level alters the growth of basil (Ocimum basilicum L.) and its content of volatile oils. Environmental and Experimental Botany, v.63, n.1, p.216-223, 2008.

FREIRE, M. F. I. Plantas medicinais: a importância do saber cultivar. Revista Cientifica Eletrônica de Agronomia, Ano III, n.5, p.1-9, 2004.

GREGORIOU, K.; PONTIKIS, K.; VEMMOS, S. Effects of reduced irradiance on leaf morphology, photosynthetic capacity, and fruit yield in olive (Olea europaea
L.). Photosynthetica, v.45, n.2, p.172-181, 2007.

LACERDA, C. F.; CARVALHO, C. M.; VIEIRA, M. R.; NOBRE, J. G.; NEVES, A. L.; RODRIGUES, C. F. Análise de crescimento de milho e feijão sob diferentes condições de sombreamento. Revista Brasileira de Ciências Agrárias, v.5, n.1, p.18-24, 2010.

LORENZI, H.; MATOS, F. J. A. Plantas medicinais no Brasil: nativas e exóticas. São Paulo: Nova Odessa, Instituto Plantarum, $2^{\mathrm{a}}$ ed, p.544, 2008.

LUNZ, A. M. P.; SILVA JÚNIOR, E. C.; DE OLIVEIRA, L. C. Efeito de diferentes níveis de sombreamento no crescimento inicial de Unha de gato (Uncaria tomentosa Willd.). Revista Brasileira de Plantas Medicinais, v.16, n.4, p.866-873, 2014.

MATTANA, R. S.; MING, L. C.; MARCHESE, J. A.; MARQUES, M. O. M. Biomass production in plants of Pothomorphe umbellate (L.) Miq. submitted to differents shade levels. Revista Brasileira de Plantas Medicinais, v.8, n. esp., p.83-85, 2006.

MELO-ABREU, P.; SNYDER, R. L.; RIBEIRO, A. C. Modeling radiation transmission interception and reflection in a hedgerow apple orchard in the northeastern Portugal. Acta Horticulturae, v.32, n.1, p.7380, 2002.

MORAIS, L. A. S. Influência dos fatores abióticos na composição química dos óleos essenciais. Horticultura brasileira, v.27, n.2, p.4050-4063, 2009.

OLIVEIRA, M. I.; CASTRO, E. M.; COSTA, L. C. B.; OLIVEIRA, C. Características biométricas, anatômicas e fisiológicas de Artemisia vulgaris L. cultivada sob telas coloridas. Revista Brasileira de Plantas Medicinais, v.11, n.1, p.56-62, 2009.

SCHAFER, V. F. Produção de alface na região mesoclimática de Santa Maria, RS. 
2009. 69 f. Tese de Doutorado. Universidade de São Paulo.

SCHLÜTER, U.; MUSCHAK, M.; BERGER, D.; ALTMANN, T. Photosynthetic performance of an Arabidopsis mutant with elevated stomatal density (sdd1-1) under different light regimes. Journal of Experimental Botany, v.54, n.383, p.867-874, 2003.

SILVA, F. G.; PINTO, J. E. B. P.; CARDOSO, M. D. G.; NASCIMENTO, E. A.; NELSON, D. L.; SALES, J. D. F.; MOL, D. J. D. S. Influence of radiation level on plant growth, yield and quality of essential oil in carqueja. Ciência e Agrotecnologia, v.30, n.1, p.52-57, 2006.

SOUZA, G. S.; SILVA, J. S.; OLIVEIRA, U. C.; LIMA, J. C.; SANTOS, A. R. Rendimento de biomassa de plantas de erva-cidreira (Melissa officinalis L.) cultivada sob diferentes ambientes de luz e doses de fósforo. Enciclopédia Biosfera, Centro Científico Conhecer, v.8, n.15, p.1516-1526, 2012.

SOUZA, M. F.; GOMES, P. A.; SOUZA JÚNIOR, I. T.; FONSECA, M. M.; SIQUEIRA, C. S.; FIGUEIREDO, L. D.; MARTINS, E. R. Influência do Sombreamento na Produção de Fitomassa e Óleo Essencial em Alecrim-pimenta (Lippia sidoides Cham). Revista Brasileira de Biociências, v.5, n.2, p.108-110, 2007. 